EGU2020-17916, updated on 09 Mar 2020

EGU General Assembly 2020

(c) Author(s) 2020. This work is distributed under

the Creative Commons Attribution 4.0 License.

\title{
Ammonium adsorption by chabazite zeolite-tuff from swine manure for soil amendment
}

Giulio Galamini, Giacomo Ferretti, Valeria Medoro, Nicola Tescaro, Barbara Faccini, and Massimo Coltorti

University of Ferrara, Department of Physics and Earth Science, Ferrara, Italy (gImgli@unife.it)

The use of natural sorbent geomaterials, like zeolitites (rocks containing $>50 \%$ of zeolites) is recognized as a valid method to recover $\mathrm{N}$ in the form of ammonium ions $\left(\mathrm{NH}_{4}^{+}\right)$from Zootechnical Wastewaters (ZoWs).

Using zeolite-rich tuff as $\mathrm{N}$ sorbent from ZoWs lead to varius advantages like the decrease in environmental impact of ZoWs (decreased $\mathrm{N}$ content) and the subsequent creation of a high-value soil amendment employable also in organic agriculture ( $\mathrm{NH}_{4}$-charged zeolite-tuff).

In order to understand the characteristics of $\mathrm{NH}_{4}$-charged zeolites (CZ) as sorbent, it is mandatory a deep investigation on their sorption dynamics when they react with ZoWs. Scientific literature is rich of studies about sorption in sintetic solutions (especially $\mathrm{NH}_{4} \mathrm{CL}$ ) while it lacks studies about sorption in real ZoWs.

The aim of this work was therefore to characterize the $\mathrm{NH}_{4}$ sorption dynamics of a chabazite zeolite tuff from swine manure. In particular, two grain sizes were selected, a micronized $(<125$ $\mu \mathrm{m}, \mathrm{CHA} \mu)$ and a granular one (0.7-2.0 mm, CHAg). A series of batch experiments were performed to investigate the effects of temperature, contact time and grain size on sorption of $\mathrm{NH}_{4}$. Equilibrium data were fitted with appropriate isothermal models; kinetic models were also investigated to characterize the kinetik sorption reactions and the thermodinamic parameters like change in free energy $(\Delta \mathrm{G})$, enthalpy $(\Delta \mathrm{H})$ and entropy $(\Delta \mathrm{S})$.

Results have shown a significant grain size effect with respect to the equilibrium loading (qe), with better performances for $\mathrm{CHA} \mu$ in all the temperatures investigated; the isothermal data showed that the influence of temperature is less for $\mathrm{CHA} \mu$ with respect to $\mathrm{CHAg}$.

The kinetic data differs from the two grain size investigated, in particular CHAg showed an initial external surface adsorption and macropore diffusion during the first 60 minutes of contact, then the diffusion occurs also inside the micropores. The Intraparticle Diffusion model (ID) for CHA $\mu$ showed that the diffusion in the macropores are much more fast than $\mathrm{CHAg}$ and the intercept indicates the formation of a boundary layer thicker than CHAg. Pseudo-second-order kinetic model well explained $\mathrm{CHAg}$ behavior but not that of $\mathrm{CHA} \mu$. Both grain sizes were well explained by Elovich equation wich is a model used to explain the sorption kinetics for energetically heterogeneous solids surfaces (as likely the surface of the zeolite-tuff employed). 
Thermodinamic data showed that the energy in the liquid-solid adsorption surfaces increased during adsorption $(\Delta \mathrm{H} \cup 0)$, thus the cation exchange reaction needs energy from the liquid phase.

The free standard entropy change $(\Delta \mathrm{S})$ is also positive, indicating that the $\mathrm{NH}_{4}$ sorption is a directional process with no significant differences with respect to the tested temperatures and that the randomness at the solid-solution interface increased during adsorption.

The negative values of Gibbs free energy $(\Delta \mathrm{G})$ indicates that the $\mathrm{NH}_{4}$ sorption is an exergonic process (spontaneous reaction). 